\title{
Laminarin Promotes Immune Responses and Normalizes Glutamic Oxaloacetic Transaminase and Glutamic Pyruvic Transaminase Levels in Leukemic Mice In Vivo
}

\author{
HUNG-SHENG SHANG ${ }^{1,2^{*}}$, YUNG-LUEN SHIH ${ }^{3,4,5^{*}}$, CHAO-PING CHEN ${ }^{1}$, \\ MEI-HUI LEE ${ }^{6}$, HSU-FENG LU ${ }^{7,8}$, PEI-YI CHOU ${ }^{8}$, NIEN-CHIEH LIAO ${ }^{8}$, \\ YUNG-LIANG CHEN ${ }^{9}$, SHU-CHING HSUEH ${ }^{10,11 \#}$ and JING-GUNG CHUNG ${ }^{12,13 \#}$ \\ ${ }^{1}$ Graduate Institute of Clinical of Medicine, College of Medicine, \\ ${ }^{4}$ School of Medical Laboratory Science and Biotechnology, Taipei Medical University, Taipei, Taiwan, R.O.C.; \\ ${ }^{2}$ Division of Clinical Pathology, Department of Pathology, Tri-Service General Hospital, \\ National Defense Medical Center, Taipei, Taiwan, R.O.C.; \\ ${ }^{3}$ Department of Pathology and Laboratory Medicine, Shin Kong Wu Ho-Su Memorial Hospital, Taipei, Taiwan, R.O.C.; \\ ${ }^{5}$ School of Medicine, College of Medicine, ${ }^{7}$ Department of Restaurant, \\ Hotel and Institutional Management, Fu-Jen Catholic University, New Taipei, Taiwan, R.O.C.; \\ ${ }^{6}$ Department of Genetic Counseling Center, Changhua Christian Hospital, Changhua, Taiwan, R.O.C.; \\ ${ }^{8}$ Department of Clinical Pathology, ${ }^{10}$ Division of Hematology and Oncology, \\ ${ }^{11}$ Department of Family Medicine and Community Medicine, Cheng Hsin General Hospital, Taipei, Taiwan, R.O.C.; \\ ${ }^{9}$ Department of Medical Laboratory Science and Biotechnology, Yuanpei University, Hsinchu, Taiwan, R.O.C.; \\ ${ }^{12}$ Department of Biological Science and Technology, China Medical University, Taichung, Taiwan, R.O.C.; \\ ${ }^{13}$ Department of Biotechnology, Asia University, Taichung, Taiwan, R.O.C.
}

\begin{abstract}
Background/Aim: Laminarin, mainly found in the fronds of Laminaria, has antimicrobial characteristics and induces immune responses. However, there are no available information to show the laminarin effect on glutamic oxaloacetic transaminase (GOT) and glutamic pyruvic transaminase (GPT) levels in mice with leukemia in vivo. Materials and Methods: Fifty normal BALB/c mice were separated randomly into five groups. Group I mice received normal diet as control. Leukemia was generated in groups II-
\end{abstract}

This article is freely accessible online.

*\#These Authors contributed equally to this study.

Correspondence to: Jing-Gung Chung, Ph.D., Department of Biological Science and Technology, China Medical University. No 91, Hsueh-Shih Road, Taichung, Taiwan, R.O.C. Tel: +886 422053366 ext. 8000, Fax: +886 422053764, e-mail: jgchung@mail.cmu.edu.tw and Shu-Ching Hsueh, Division of Hematology and Oncology, ChengHsin General Hospital, No. 45, Cheng Hsin St., Pai-Tou, Taipei, Taiwan, R.O.C. Tel: +886 228264400 ext. 5850, Fax: +886 228264517,e-mail: ch1835@chgh.org.tw

Key Words: Laminarin, leukemia BALB/c mice, glutamic oxaloacetic transaminase, glutamic pyruvic transaminase, immune response.
V using WEHI-3 cells: Group II mice received normal diet as positive control; group III, IV and $V$ mice received laminarin at $1,2.5$ and $5 \mathrm{mg} / \mathrm{ml}$ with $d d \mathrm{H}_{2} \mathrm{O}$, respectively, by oral gavage every 2 days for 14 days (total of seven times). All mice were weighed during the treatment. After treatment, mice were sacrificed, blood was collected for determination of cell markers, liver and spleen samples were weighed, and spleens were used for phagocytosis and natural killer (NK) cell activity and cell proliferation using flow cytometric assay. Results: Laminarin did not affect animal appearances, but increased the body weight at all doses. It reduced the weight of liver at 2.5 and $5 \mathrm{mg} / \mathrm{ml}$ and of spleen at $5 \mathrm{mg} / \mathrm{ml}$. Laminarin increased CD3 $(2.5 \mathrm{mg} / \mathrm{ml})$ and $C D 19(1$ and $5 \mathrm{mg} / \mathrm{ml})$ cell populations but reduced CD11b (5 $\mathrm{mg} / \mathrm{ml})$ cell populations, however, these did not affect Mac-3 marker level. Laminarin at $1 \mathrm{mg} / \mathrm{ml}$ increased phagocytosis by macrophages from peripheral blood mononuclear cell, but did not affect those from the peritoneal cavity. Laminarin increased NK cell cytotoxic activity at all doses and at a target ratio of 25:1 and 50:1. Laminarin did not affect B-cell proliferation, but at $5 \mathrm{mg} / \mathrm{ml}$ significantly reduced T-cell proliferation. Laminarin restored glutamate oxaloacetate transaminase $(2.5$ and $5 \mathrm{mg} / \mathrm{ml})$ and glutamate pyruvate transaminase $(2.5 \mathrm{mg} / \mathrm{ml})$ levels. Based on these results, we suggest that laminarin can promote immune responses and protect against liver injury. 
Acute myeloid leukemia (AML) is an aggressive form of cancer of the bone marrow and blood which is characterized by an accumulation of immature myeloid blasts in the bone marrow (1) and is the most common acute leukemia in adults (2). However, progress in understanding AML and novel treatment concepts are inadequate (3). The two standard treatments for patients with AML are chemotherapy and hematopoietic stem cell transplantation, however, the 5-year survival rate remains below $50 \%$ due to chemoresistance or toxicity from these treatments (4-6). Numerous studies have focused on finding or developing novel therapeutic strategies or agents for such patients. Improving immune responses to mediate protection against leukemia $(7,8)$ is needed. There is also focus on finding and improving immune responses from natural products.

Laminarin, beta-1,3-glucan, a typical component of fungal cell walls (9), found mainly in the fronds of Laminaria, has antimicrobial properties (10). It also induces defense-related events against Tobacco mosaic virus in tobacco and grapevine (11-13). Injections of laminarin to both adult and larval locusts lead to stimulate the immune responses $(14,15)$. Laminarin has also been shown to inhibit heparanase activity and tumor metastasis (16), and can boost the immune system, reduce cholesterol level and lower systolic blood pressure (17). It was reported that the pro-inflammatory chemokines such as interleukin-8 (IL8) and monocyte chemoattractant protein-1 (CCL2) are secreted in human intestinal epithelial cells after exposure to laminarin (18). Laminarin influenced the adherence and the translocation of bacteria across the epithelial wall (in jejunum, ileum, caecum and colon) of Wistar rat (Rattus norvegicus). (19). In fish, laminarin increased the expression of immune response genes $I L 1 \beta, I L 8$, and toll-like receptor 2 (TLR2), therefore, it was suggested that laminarin modulates the immune response and stimulates growth of fish (20). Based on these observations, laminarin extracts have great potential as a supplement in functional food.

Herein, we investigated the effects of laminarin on immune responses in leukemic BALB/c mice in vivo.

\section{Materials and Methods}

Materials and reagents. Laminarin and dimethyl sulfoxide (DMSO) were purchased from Sigma-Aldrich Corp. (St. Louis, MO, USA). Iscove's modified Dulbecco's medium (IMDM), Roswell Park Memorial Institute (RPMI)-1640 media, L-glutamine, penicillinstreptomycin and fetal bovine serum (FBS) were purchased from Gibco Life Technologies (Carlsbad, CA, USA). Antibodies against CD3, CD11b, CD19 and lysosomal-associated membrane protein 2 (Mac-3) were purchased from BD Biosciences Pharmingen Inc. (San Diego, CA, USA). Laminarin was dissolved in double-distilled water $\left(\mathrm{ddH}_{2} \mathrm{O}\right)$ and stored at room temperature for $1 \mathrm{~h}$ before use.

WEHI-3 cells. Murine acute myelomonocytic leukemia WEHI-3 cell line was obtained from the Food Industry Research and Development Institute (Hsinchu, Taiwan, ROC). Cells were cultured with IMDM supplemented with $10 \%$ FBS, $2 \mathrm{mM}$ L-glutamine and antibiotics (100 units $/ \mathrm{ml}$ penicillin, $100 \mu \mathrm{g} / \mathrm{ml}$ streptomycin) in $75 \mathrm{~cm}^{2}$ tissue culture flasks and placed at $37^{\circ} \mathrm{C}$ in a humidified atmosphere of $5 \%$ $\mathrm{CO}_{2}(21)$.

Male BALB/c mice. Fifty male BALB/c mice around 20-23 g at 4 weeks old were obtained from the National Laboratory Animal Center (Taipei, Taiwan, ROC). All mice were kept in stainless steel mesh-bottomed cages and were maintained with specified pathogenfree conditions at the animal center of China Medical University (Taichung, Taiwan, ROC). For all mice, the institutional guidelines for animal welfare of China Medical University were followed and the study was approved by the Institutional Animal Care and Use Committee of China Medical University (Taichung, Taiwan) (approval ID: 104-11-B).

Treatment of animals with laminarin. Fifty BALB/c mice were randomly separated into five groups $(\mathrm{N}=10)$ : Group I were normal animals with normal diet as control; groups II-V were given a peritoneal injection with $8 \times 10^{4}$ WEHI-3 leukemia cells. Group II mice received normal diet as positive control; group III, IV and V mice received laminarin at $1,2.5$ and $5 \mathrm{mg} / \mathrm{ml}$ with $\mathrm{ddH}_{2} \mathrm{O}$, respectively, by oral gavage every 2 days for 14 days (total of seven times). All animals were individually weighed during the oral treatment, and at the end of treatment, all mice were weighed and sacrificed as described previously (21).

Measurements of cell populations. At the end of treatment, all mice were individually weighed, and the blood sample, liver and spleen organs were individually collected. A sample of $1 \mathrm{ml} \mathrm{blood} / \mathrm{mouse}$ was lysed with $1 \mathrm{X}$ Pharm Lyse ${ }^{\mathrm{TM}}$ lysing buffer (BD Biosciences Pharmingen Inc., San Diego, CA, USA) for destroying the red blood cells as per the guideline from BD Biosciences. Leukocytes were collected and stained with phycoerythrin (PE)-labeled anti-mouse CD3 and CD19, and fluorescein isothiocyanate (FITC)-labeled antimouse CD11b and Mac-3 antibodies (BD Biosciences Pharmingen Inc.) for $30 \mathrm{~min}$. All samples were washed with phosphate-buffered saline (PBS) and cell markers (populations) were analyzed by flow cytometry as previously described $(21,22)$.

Measurements of macrophage phagocytosis. All macrophages were isolated from peripheral blood mononuclear cells (PBMCs) and peritoneum as described previously $(21,22)$. All macrophages were placed in plates containing $50 \mu \mathrm{l}$ of target FITC-labelled Escherichia coli and were mixed and then were analyzed for phagocytosis by using flow cytometery following the PHAGOTEST ${ }^{\circledR}$ kit manufacturer's instructions (ORPEGEN Pharma Gesellschaft für biotechnologische, Heidelberg, Germany). Quantifying phagocytosis was performed by CellQuest software (Becton Dickinson) as described previously (22).

Measurements of natural killer (NK) cell cytotoxic activity. Isolated splenocytes were maintained in 96 -well plate $\left(2.5-5 \times 10^{5}\right.$ cells/well $)$ with $100 \mu \mathrm{l}$ of RPMI-1640 medium. Target YAC- 1 cells $\left(1 \times 10^{4}\right.$ cells $)$ and PKH-67/Dil.C buffer were added to each well (Sigma-Aldrich Corp.) for $2 \mathrm{~min}$ at $25^{\circ} \mathrm{C}$. Two milliliters of PBS was added to each well for $1 \mathrm{~min}$, then $4 \mathrm{ml}$ medium was also added to the well and plates were incubated for $10 \mathrm{~min}$. After incubation, all samples were centrifuged at $290 \times \mathrm{g}$ for $2 \mathrm{~min}$. NK cell cytotoxic activity was measured by flow cytometry as described elsewhere (22). 

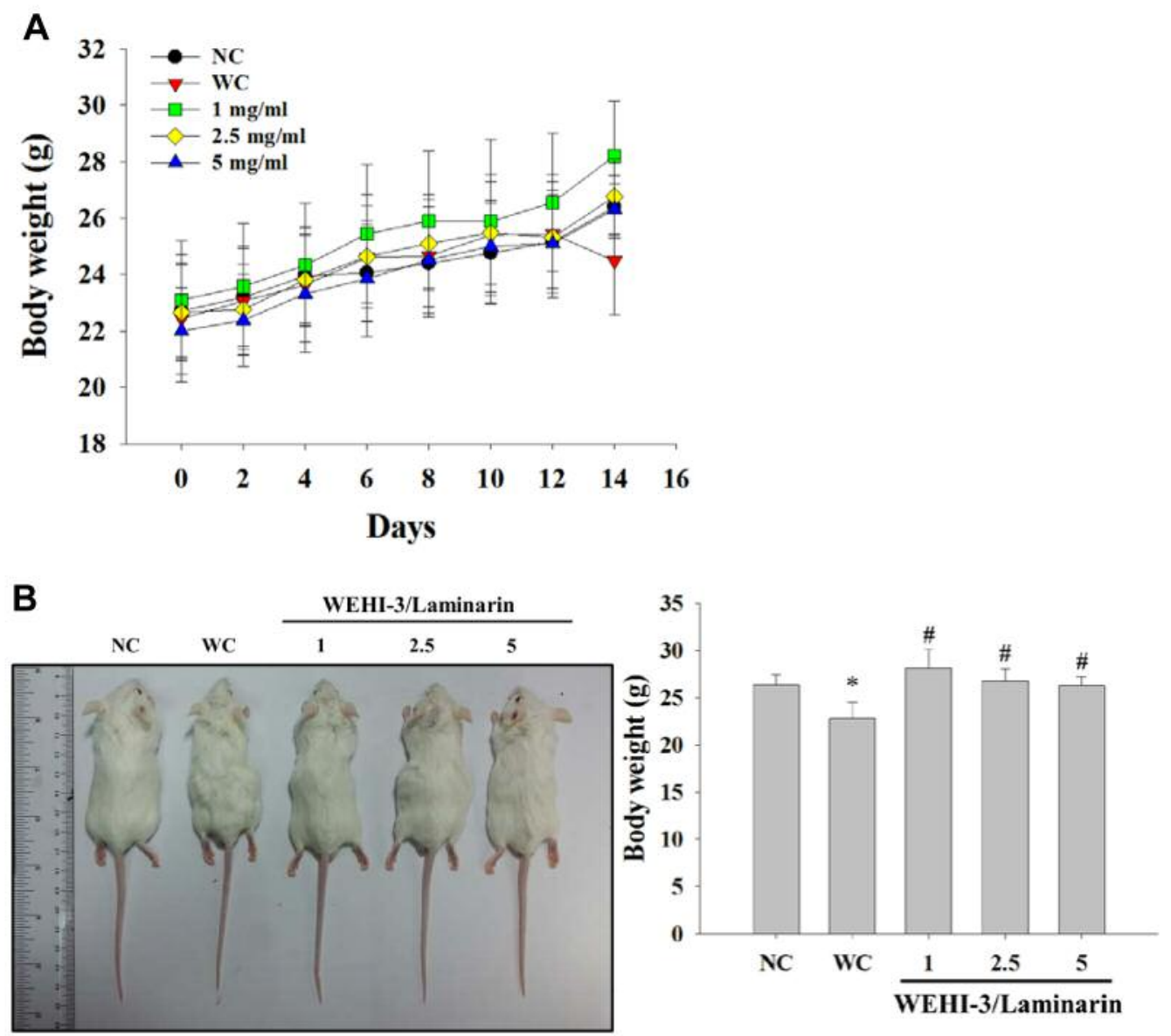

C
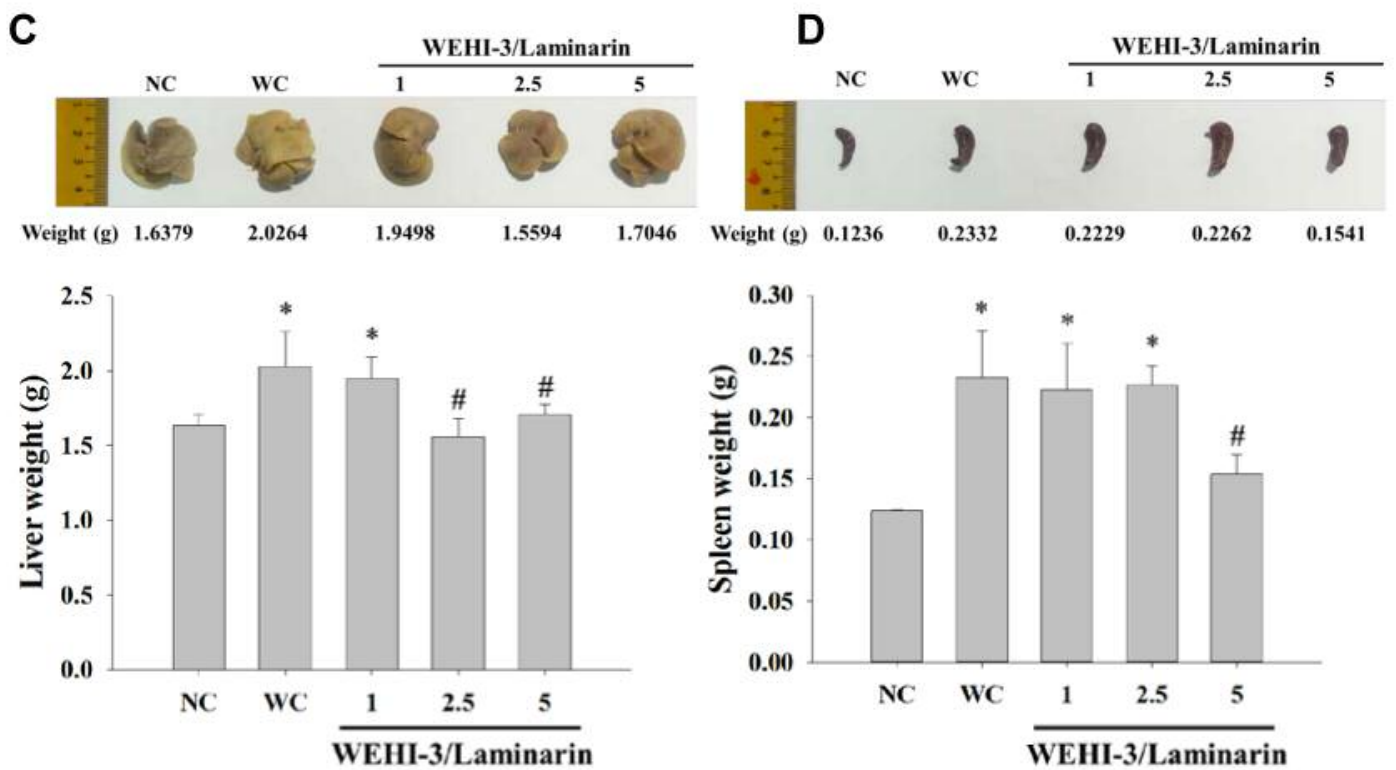

Figure 1. Laminarin affected the body, liver and spleen weights of leukemic BALB/c mice. Fifty mice were randomly separated into five groups $(N=10)$ : Group I were normal animals with normal diet as control; groups II-V were given a peritoneal injection with $8 \times 10^{4}$ WEHI-3 leukemia cells. Group II mice received normal diet as positive control; group III, IV and V mice received laminarin at $1,2.5$ and $5 \mathrm{mg} / \mathrm{ml}$ with dd $\mathrm{H}_{2} \mathrm{O}$, respectively, by oral gavage every 2 days for 14 days (total of seven times). A: Body weight during the experiment. B: Final animal appearance and weight. C: Representative examples of liver and weight. D: Representative examples of spleen and weight. Significantly different at p $<0.05$ vs. *normal control (NC) group and \#leukemic control (WC) group. 
A

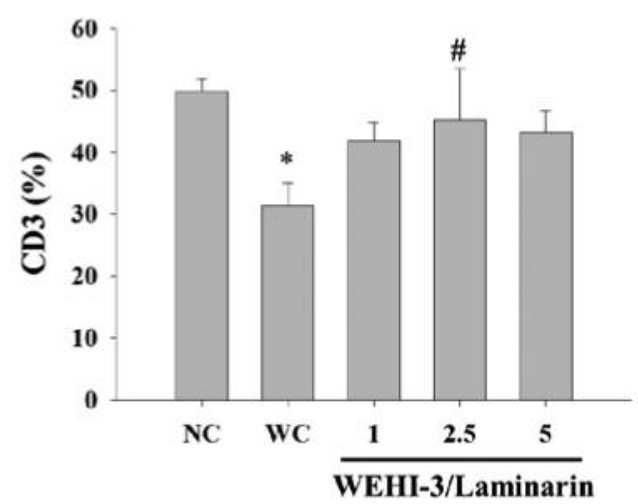

C

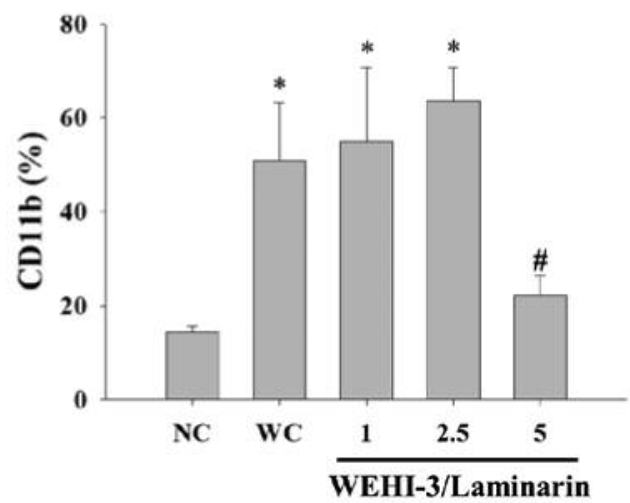

B

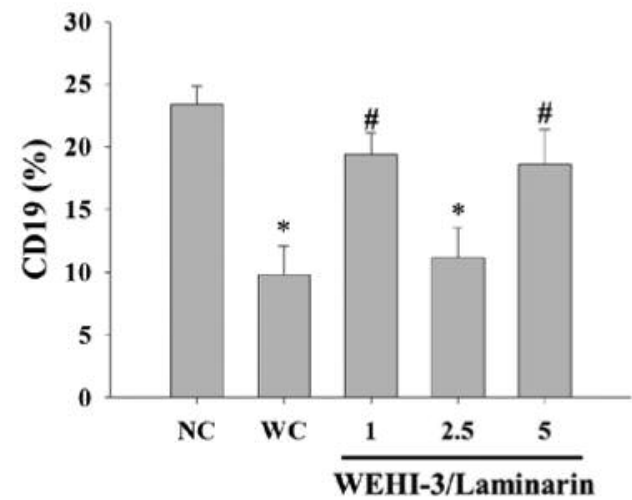

D

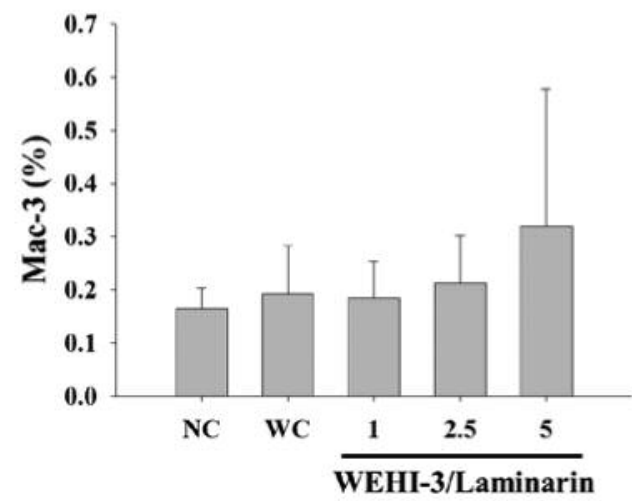

Figure 2. Laminarin affected the levels of cell markers in white blood cells from leukemic BALB/c mice. Blood was collected from all mice and was analyzed for cell markers by flow cytometry as described in the Materials and Methods. A: CD3. B: CD19. C: CD11b and D: Mac-3. Significantly different at $p<0.05$ vs. *normal control (NC) group and \#leukemic control (WC) group.

Measurements of T-and B-cell proliferation. Isolated splenocytes $\left(100 \mu \mathrm{l}, 1 \times 10^{5}\right.$ cells/well) were added to a plate with 96 wells which each contained $100 \mu \mathrm{l}$ of RPMI-1640 medium. Concanavalin A (5 $\mu \mathrm{g} / \mathrm{ml}$ ) was added to stimulate the cells for 5 days in order to measure T-cell proliferation. Lipopolysaccharide (LPS, $5 \mu \mathrm{g} / \mathrm{ml}$ ) was added to stimulate the cells for 3 days in order to measure Bcell proliferation. All samples were measured for cell proliferation using CellTiter 96 AQueous One Solution Cell Proliferation Assay kit (Promega, Madison, WI, USA) as previously described (22).

Measurement of blood glutamic oxaloacetic transaminase (GOT) and glutamic pyruvic transaminase (GPT). Blood samples were used for measurement of the levels of GOT and GTP by using liquiUV Test (aspartate aminotransferase) for GOT, and liquiUV Test (alanine aminotransferase) for GPT from Human Gesellschaft fur Biochemica und Diagnosica mbH (Wiesbaden, Germany) (22-24).

Statistical analysis. Data are expressed as mean \pm standard deviation (SD). Comparisons differences between groups were analyzed by one-way analysis of variance and Tukey test for multiple comparisons (SigmaPlot for Windows version 12.0; Systat Software, Inc., San Jose, CA, USA). Values of $p<0.05$ were considered to indicate a statistically significant difference.

\section{Results}

Laminarin affected the weights of body, liver and spleen from leukemic $B A L B /$ c mice. Representative animal body weights, liver and spleen samples and weights are present in Figure 1. An increase in weight gained by laminarin-treated groups when compared with positive control group was observed (Figure 1A). Laminarin did not significantly affect animal appearance but increased final body weight when compared with the positive control group (Figure 1B). When compared with the positive control group, laminarin significantly reduced liver weight at 2.5 and $5 \mathrm{mg} / \mathrm{ml}$ treatment (Figure 1C) and spleen weight (Figure 1D) at $5 \mathrm{mg} / \mathrm{ml}$ treatment. 
A

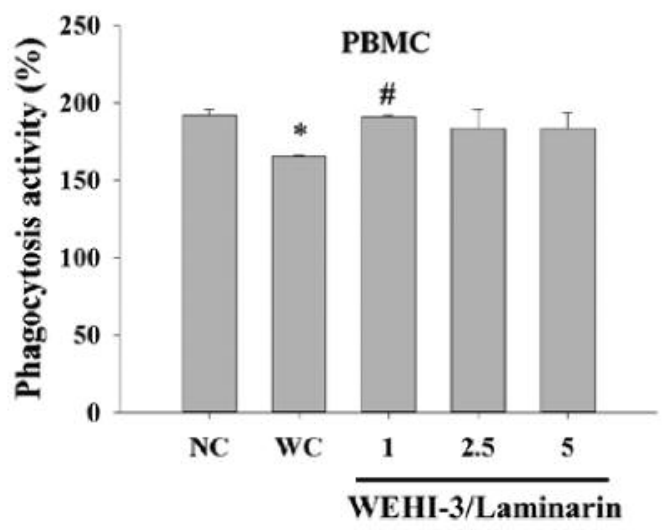

B

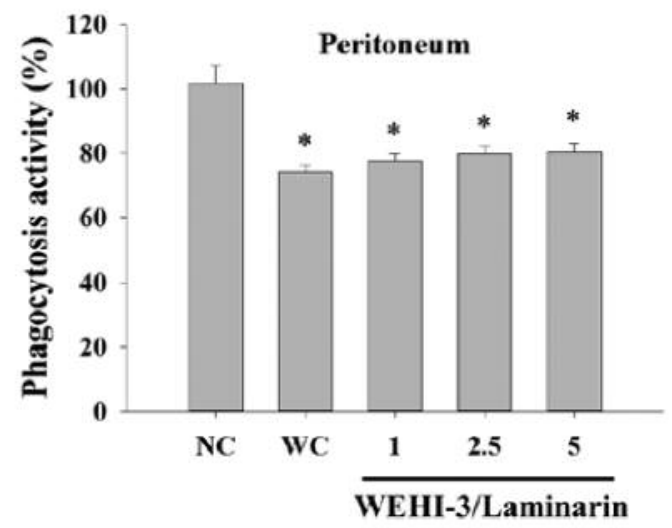

Figure 3. Laminarin affected phagocytosis by macrophages from peripheral blood mononuclear cells (PBMCs) and peritoneal cavity of leukemic $B A L B / c$ mice. Blood samples were collected from mice and macrophages were isolated from PBMCs (A) and peritoneum (B) of each mouse. Phagocytosis was measured by flow cytometery and quantified by CellQuest as described in the Materials and Methods. Significantly different at p<0.05 vs. *normal control (NC) group and \#leukemic control (WC) group.

Laminarin affected white blood cell markers from leukemic $B A L B / c$ mice. Blood samples were assayed for the levels of cell markers CD3, CD19, CD11b and Mac-3 by flow cytometry. The results indicate that laminarin promoted expression of CD3 at $2.5 \mathrm{mg} / \mathrm{ml}$ (Figure 2A) and CD19 at 1 and $5 \mathrm{mg} / \mathrm{ml}$ (Figure 2B), and reduced that of CD11b at 5 $\mathrm{mg} / \mathrm{ml}$ treatment (Figure $2 \mathrm{C}$ ) but did not significantly affect that of Mac-3 (Figure 2D) when compared with the positive control group.

Laminarin affected phagocytosis by macrophages from $P B M C$ s and peritoneal cavity of leukemic BALB/c mice. Macrophages were isolated from PBMCs and peritoneal cavity to measure the percentage of phagocytosis. Laminarin treatment at $1 \mathrm{mg} / \mathrm{ml}$ significantly increased phagocytosis from macrophages from PBMCs (Figure 3A), however, none of the three doses of laminarin affected phagocytosis from macrophages of the peritoneal cavity when compared with the positive control group (Figure 3B).

Laminarin affected the cytotoxic activity of $N K$ cells from leukemic BALB/c mice. For measuring the NK cell activity, YAC-1 cells were used as targets and were assayed by flow cytometry. The results indicate that laminarin significantly increased NK cell cytotoxic activity at all laminarin doses and both target ratios (25:1 and 50:1) when compared to the positive control group (Figure 4).

Laminarin affected proliferation of $T$-and B-cells from leukemic $B A L B / c$ mice. Isolated splenocytes were assayed for

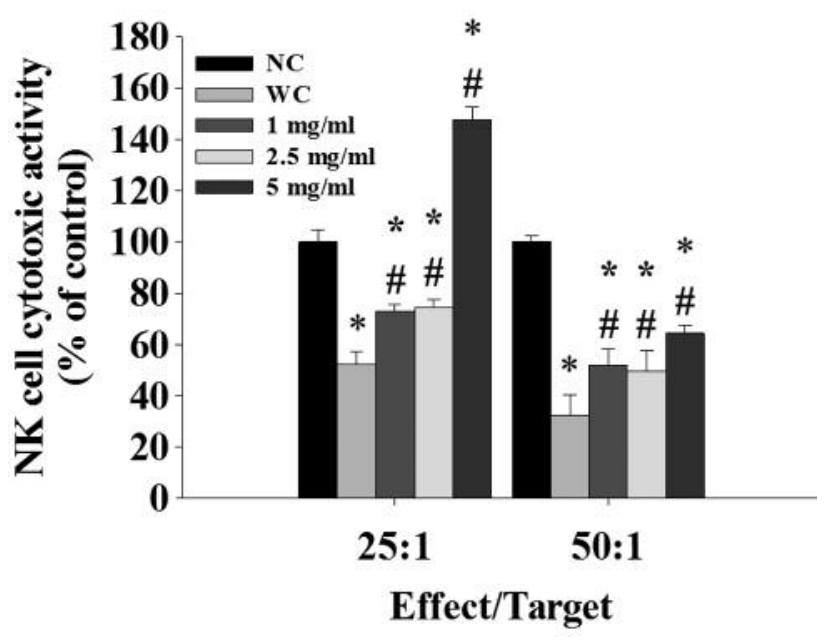

Figure 4. Laminarin affected the cytotoxic activity of natural killer (NK) cells in leukemic BALB/c mice. Isolated splenocytes were placed in $1 \mathrm{ml}$ of RPMI 1640 medium in 96-well plates. Target YAC-1 cells with serumfree RPMI 1640 medium and PKH-67/Dil.C buffer was added to the cells and NK cell cytotoxic activity was measured by flow cytometry as described in the Materials and Methods. Significantly different at $p<0.05$ vs. *normal control (NC) group and \#leukemic control (WC) group.

T-and B-cell proliferation. The results indicate that laminarin at $5 \mathrm{mg} / \mathrm{ml}$ significantly reduced T-cell proliferation (Figure $5 \mathrm{~A})$, however, none of the treatments significantly affected B-cell proliferation (Figure 5B) when compared with the positive control group. 
Laminarin affect the blood GOT and GPT levels of leukemic $B A L B / c$ mice. Blood sample were collected for measuring the levels of GOT and GTP. GOT and GTP levels were significantly elevated in untreated leukemic mice (positive control) compared with the healthy mice of the negative control group. Treatment with laminarin at 2.5 and $5 \mathrm{mg} / \mathrm{ml}$ restored GOT to a relatively normal level (Figure 6A) and at $2.5 \mathrm{mg} / \mathrm{ml}$ restored the GPT level (Figure 6B) when compared with the positive control.

\section{Discussion}

It has been reported that the binding of laminarin to an amino-terminal $\beta$-1,3-glucan binding domain (N- $\beta$ GRP) from Plodia interpunctella ( $P i-\mathrm{N}-\beta \mathrm{GRP})$ can induce the formation of a protein-carbohydrate macrocomplex containing multiple $P i$-N- $\beta$ GRP molecules; it was suggested that this complex is an initiation signal for activation of serine protease cascades that promote immune responses (10). Our earlier studies, we showed that laminarin promotes immune responses and reduces lactate dehydrogenase but increases GPT in hormal mice in vivo (25). However, the exact immune response to laminarin treatment in leukemic mice was not clear. To our knowledge, this is the first study evaluating the effect of laminarin on immune responses in leukemic mice in vivo.

Cell population assay from blood samples of treated mice indicated that laminarin elevated the expression of $\mathrm{CD} 3$ (Figure 2A) and CD19 (Figure 2B), but reduced that of CD11b (Figure 2C). It is well known that T-cells (CD3+), Bcells $(\mathrm{CD} 19+)$ and monocytes $(\mathrm{CD} 11 \mathrm{~b}+)$ play critical roles in immune responses (26). Immune responses can be divided into innate and adaptive immune responses; during viral infection, viral replication is initially controlled by innate immunity before adaptive immune responses (T-cell and B-cell) for host recovery (27). Mac-3 is a marker of macrophages (28). Herein, results did not show that laminarin significantly increased the Mac-3 level when compared to control groups. Laminarin reduced the $\mathrm{CD} 11 \mathrm{~b}^{+}$number, thus reducing the population of monocytes. In order to further investigate the effects of laminarin on the activities of macrophage, we used the $E$. coli target cells. These cells were added to the macrophages from PBMCs and peritoneum. Laminarin increased phagocytosis from macrophages from PBMCs (Figure 3A). It is well known that one of the factors for pathogen clearance by macrophages is a high level of ROS production when they are in contact with pathogen (29-32).

Laminarin significantly increased NK cell cytotoxic effect in leukemic mice (Figure 4), reduced T-cell proliferation at $5 \mathrm{mg} / \mathrm{ml}$ treatment after stimulation (Figure 5A), but did not significantly affect B-cell proliferation after stimulation (Figure 5B). B-Cells play an important role in producing antibody against antigens. NK cells are also important
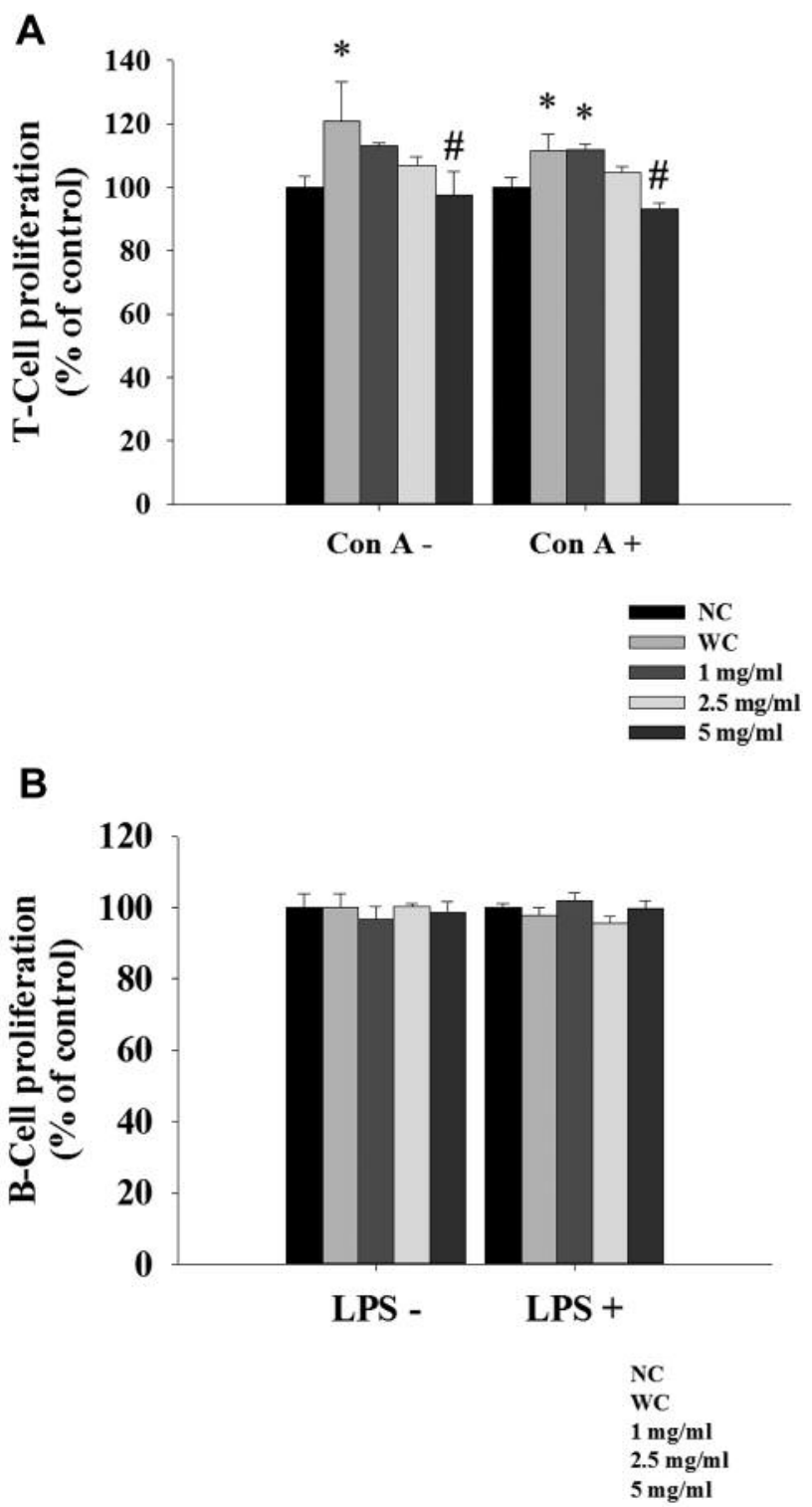

Figure 5. Laminarin affected $T$ - and B-cell proliferation in leukemic $B A L B / c$ mice. Isolated cells were stimulated with concanavalin $A(C o n$ A) for proliferation of T-cells (A) and with lipopolysaccharide (LPS) for $B$-cells $(B)$, and then were analyzed by flow cytometry as described in the Materials and Methods. Significantly different at $p<0.05 v s$. *normal control (NC) group and \#leukemic control (WC) group.

immune cells in innate immunity, herein, we used targeting of YAC-1 cells for measuring NK cell cytotoxic activity which is a well-documented protocol.

Laminarin restored GOT and GPT levels although at different doses. In serum, the levels of GPT and GOT activity are higher than normal levels, that may reflect hepatic cell destruction (33). 
A

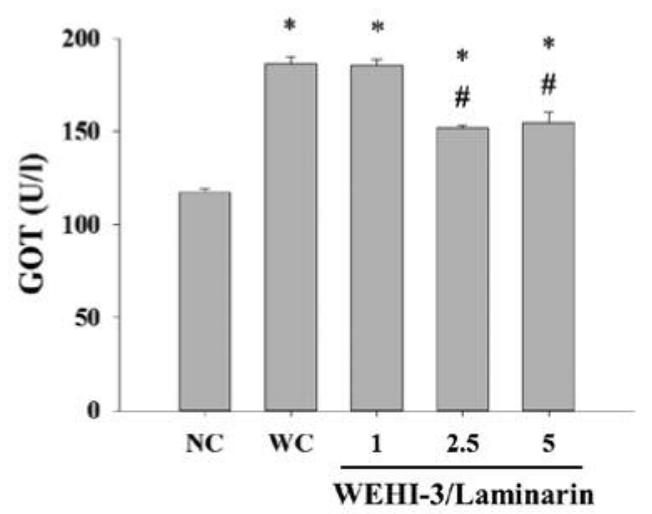

B

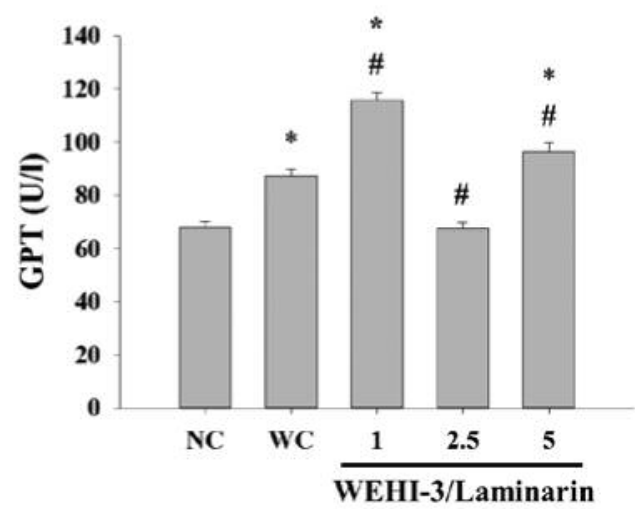

Figure 6. Effects of laminarin on serum biochemical values in leukemia BALB/c mice. Measurement of glutamic oxaloacetate transaminase (GOT) (A) and glutamic pyruvate transaminase $(G P T)(B)$ in the blood of leukemic BALB/c mice following exposure to laminarin. Significantly different at $p<0.05$ vs. *normal control (NC) group and "leukemic control (WC) group.

Taken together, based on these findings, we suggest that laminarin may modulate immune responses through promoting T- and B-cell, and macrophage populations.

\section{Acknowledgements}

This study was supported by the grant 105-30 from Cheng Hsin General Hospital and 2018SKHAND008 from Shin Kong Wu Ho$\mathrm{Su}$ Memorial Hospital, Taipei, Taiwan. Experiments and data analysis were performed in part through the use of the Medical Research Core Facilities Center, Office of Research \& Development at China medical University, Taichung, Taiwan.

\section{References}

1 Dohner H, Estey E, Grimwade D, Amadori S, Appelbaum FR, Buchner T, Dombret H, Ebert BL, Fenaux P, Larson RA, Levine RL, Lo-Coco F, Naoe T, Niederwieser D, Ossenkoppele GJ, Sanz M, Sierra J, Tallman MS, Tien HF, Wei AH, Lowenberg B and Bloomfield CD: Diagnosis and management of AML in adults: 2017 ELN recommendations from an international expert panel. Blood 129: 424-447, 2017.

2 Eaves CJ and Humphries RK: Acute myeloid leukemia and the Wnt pathway. N Engl J Med 362: 2326-2327, 2010.

3 Estey E: Why is progress in acute myeloid leukemia so slow? Semin Hematol 52: 243-248, 2015.

4 Lichtenegger FS, Krupka C, Haubner S, Kohnke T and Subklewe M: Recent developments in immunotherapy of acute myeloid leukemia. J Hematol Oncol 10: 142, 2017.

5 Roboz GJ: Current treatment of acute myeloid leukemia. Curr Opin Oncol 24: 711-719, 2012.

6 Padma VV: An overview of targeted cancer therapy. BioMedicine 5: 19, 2015.

7 Stefanski HE, Jonart L, Goren E, Mule JJ and Blazar BR: A novel approach to improve immune effector responses post transplant by restoration of CCL21 expression. PLoS One 13: e0193461, 2018.
8 Kondo K, Shaim H, Thompson PA, Burger JA, Keating M, Estrov Z, Harris D, Kim E, Ferrajoli A, Daher M, Basar R, Muftuoglu M, Imahashi N, Alsuliman A, Sobieski C, Gokdemir E, Wierda W, Jain N, Liu E, Shpall EJ and Rezvani K: Ibrutinib modulates the immunosuppressive CLL microenvironment through STAT3-mediated suppression of regulatory B-cell function and inhibition of the PD-1/PD-L1 pathway. Leukemia 32: 960-970, 2018.

9 Stone BA: Chapter 2.1- Chemistry of $\beta$-Glucans. In: Chemistry, Biochemistry, and Biology of 1-3 Beta Glucans and Related Polysaccharides. San Diego: Academic Press, pp. 5-46, 2009.

10 Dai H, Hiromasa Y, Takahashi D, VanderVelde D, Fabrick JA, Kanost MR and Krishnamoorthi R: An initial event in the insect innate immune response: structural and biological studies of interactions between beta-1,3-glucan and the N-terminal domain of beta-1,3-glucan recognition protein. Biochemistry 52: 161$170,2013$.

11 Aziz A, Poinssot B, Daire X, Adrian M, Bezier A, Lambert B, Joubert JM and Pugin A: Laminarin elicits defense responses in grapevine and induces protection against Botrytis cinerea and Plasmopara viticola. Mol Plant Microbe Interact 16: 1118-1128, 2003.

12 Klarzynski O, Plesse B, Joubert JM, Yvin JC, Kopp M, Kloareg $\mathrm{B}$ and Fritig B: Linear beta-1,3 glucans are elicitors of defense responses in tobacco. Plant Physiol 124: 1027-1038, 2000.

13 Menard R, Alban S, de Ruffray P, Jamois F, Franz G, Fritig B, Yvin JC and Kauffmann S: Beta-1,3 glucan sulfate, but not beta1,3 glucan, induces the salicylic acid signaling pathway in tobacco and Arabidopsis. Plant Cell 16: 3020-3032, 2004.

14 Goldsworthy G, Opoku-Ware K and Mullen L: Adipokinetic hormone enhances laminarin and bacterial lipopolysaccharideinduced activation of the prophenoloxidase cascade in the African migratory locust, Locusta migratoria. J Insect Physiol 48: 601-608, 2002.

15 Mullen LM and Goldsworthy GJ: Immune responses of locusts to challenge with the pathogenic fungus Metarhizium or high doses of laminarin. J Insect Physiol 52: 389-398, 2006. 
16 Miao HQ, Elkin M, Aingorn E, Ishai-Michaeli R, Stein CA and Vlodavsky I: Inhibition of heparanase activity and tumor metastasis by laminarin sulfate and synthetic phosphorothioate oligodeoxynucleotides. Int J Cancer 83: 424-431, 1999.

17 Kadam SU, Tiwari BK and O'Donnell CP: Extraction, structure and biofunctional activities of laminarin from brown algae. Int J Food Sci Technol 50: 24-31, 2015.

18 Cohen-Kedar S, Baram L, Elad H, Brazowski E, Guzner-Gur H and Dotan I: Human intestinal epithelial cells respond to betaglucans via Dectin-1 and Syk. Eur J Immunol 44: 3729-3740, 2014.

19 Devillé C, Gharbi M, Dandrifosse G and Peulen O: Study on the effects of laminarin, a polysaccharide from seaweed, on gut characteristics. J Sci Food Agric 87: 1717-1725, 2007.

20 Yin G, Li W, Lin Q, Lin X, Lin J, Zhu Q, Jiang H and Huang Z: Dietary administration of laminarin improves the growth performance and immune responses in Epinephelus coioides. Fish Shellfish Immunol 41: 402-406, 2014.

21 Fan MJ, Yeh PH, Lin JP, Huang AC, Lien JC, Lin HY and Chung JG: Anthocyanins from black rice (Oryza sativa) promote immune responses in leukemia through enhancing phagocytosis of macrophages in vivo. Exp Ther Med 14: 59-64, 2017.

22 Lu HF, Tung WL, Yang JS, Huang FM, Lee CS, Huang YP, Liao WY, Chen YL and Chung JG: In vitro suppression of growth of murine WEHI-3 leukemia cells and in vivo promotion of phagocytosis in a leukemia mice model by indole-3-carbinol. J Agric Food Chem 60: 7634-7643, 2012.

23 Recommendations of the German Society for Clinical Chemistry: Standardization of methods for the determination of enzyme activities in biological fluids. Z Klin Chem Klin Biochem 8: 658-660, 1970 .

24 Nagamatsu Y, Yamamoto J, Fukuda A, Ohta M, Tsuda Y and Okada Y: Determination of leukocyte elastase concentration in plasma and serum by a simple method using a specific synthetic substrate. Haemostasis 21: 338-345, 1991

25 Shih YL, Hsueh SC, Chen YL, Chou JS, Chung HY, Liu KL, Jair HW, Chuang YY, Lu HF, Liu JY and Chung JG: Laminarin promotes immune responses and reduces lactate dehydrogenase but increases glutamic pyruvic transaminase in normal mice in vivo. In Vivo 32: 523-529, 2018.
26 Arpinati $M$ and Curti A: Immunotherapy in acute myeloid leukemia. Immunotherapy 6: 95-106, 2014.

27 Nussing S, Sant S, Koutsakos M, Subbarao K, Nguyen THO and Kedzierska K: Innate and adaptive T-cells in influenza disease. Front Med 12: 34-47, 2018.

28 Askew D, Burger CJ and Elgert KD: Modulation of alloreactivity by Mac-1+,-2+, and-3+ macrophages from normal and tumor-bearing hosts: flow cytofluorometrically separated macrophages. Immunobiology 182: 1-10, 1990.

29 Barnett TC, Lim JY, Soderholm AT, Rivera-Hernandez T, West NP and Walker MJ: Host-pathogen interaction during bacterial vaccination. Curr Opin Immunol 36: 1-7, 2015.

30 Brune B, Dehne N, Grossmann N, Jung M, Namgaladze D, Schmid T, von Knethen A and Weigert A: Redox control of inflammation in macrophages. Antioxid Redox Signal 19: 595637, 2013.

31 Leavy O: Inflammation: Regulating ROS. Nat Rev Immunol 14: 357, 2014.

32 Nathan C and Cunningham-Bussel A: Beyond oxidative stress: an immunologist's guide to reactive oxygen species. Nat Rev Immunol 13: 349-361, 2013.

33 Yamashita T, Ohshima H, Asanuma T, Inukai N, Miyoshi I, Kasai N, Kon Y, Watanabe T, Sato F and Kuwabara M: The effects of alpha-phenyl-tert-butyl nitrone (PBN) on copperinduced rat fulminant hepatitis with jaundice. Free Radic Biol Med 21: 755-761, 1996 